\title{
Perkütan endoskopik gastrostomi uygulamalarındaki tecrübelerimiz
}

\author{
Our experience in percutaneous endoscopic gastrostomy
}

Hakan DEMIRCI, Güldem KILCILER, Kadir ÖZTÜRK, Murat KANTARCIOĞLU, Ahmet UYGUN, Sait BAĞCI

Gülhane Askeri Tıp Akademisi, Gastroenteroloji Bilim Dalı, Ankara

Giriş ve Amaç: Perkütan endoskopik gastrostomi uzun vadeli enteral nutrisyona gereksinim duyan hastalarda beslenme için tercih edilen yöntemdir Bu çalıșmanın amacı, perkütan endoskopik gastrostomi uygulanan hastaların özelliklerini retrospektif olarak analiz etmektir. Gereç ve Yöntem: Gülhane Askeri Tip Akademisi, Gastroenteroloji Bilim Dalında 1999 ile 2014 yıllar arasında perkütan endoskopik gastrostomi uygulanan hastaların endikasyonları, işlem detayları, takip süreleri ve gelişen komplikasyonlar retrospektif olarak değerlendirildi. Bulgular: Çalışmaya dahil edilen 642 hastanın 405'i (\%63.1) erkek, 237'si (\%36.9) kadındı. Hastaların ortalama yaşlar 64.2 (18-97) yıl idi. Yedi hasta dışındaki tüm hastalara perkütan endoskopik gastrostomi başarıyla uygulandı. En sik perkütan endoskopik gastrostomi yerleştirme endikasyonu 495 (\%77.1) hasta ile nörolojik hastalıklardı. Diğer endikasyonlar ise; 109 (\%16.9) hastada orofaringeal hastalıklar ve 38 (\%6) hastada özofageal hastalıklardı. Perkütan endoskopik gastrostomi prosedürüne bağlı 123 (\%19.1) hastada komplikasyon gözlendi. Perkütan endoskopik gastrostomi sonrası 1 aylık dönem içinde 9 (\%1.4) hasta, 3 ay içinde 15 (\%2.3) hasta, 6 ay içinde ise 38 (\%5.9) hasta ex oldu. Perkütan endoskopik gastrostomi yerleştirilmesine bağlı hiçbir hastada mortalite gözlenmedi. Sonuç: Perkütan endoskopik gastrostomi, beslenme desteğinin enteral olarak sağlanmasında güvenli, minimal invaziv, etkili, iyi tolere edilen ve düşük komplikasyon oranına sahip bir uygulamadır.

Anahtar Kelimeler: Perkütan endoskopik gastrostomi, enteral beslenme, endikasyon

\section{GİRİs}

Perkütan endoskopik gastrostomi (PEG), farklı sebeplerle oral yoldan beslenemeyen ancak gastrointestinal sistem fonksiyonları normal olan hastalarda enteral beslenmenin sağlanabilmesi için uygulanabilecek bir yöntemdir. Ilk olarak 1980 yılında Gauderer ve Ponsky tarafından Amerika Birleşik Devletlerinde uygulanmıştır (1). Enteral beslenmeyi devam ettirmek açısından en önemli ve kullanışlı uygulama PEG'dir. Fakat PEG dışında çeşitli yollar da bulunmaktadır. Bunlardan bazıları nazogastrik beslenme tüpü, nazojejunal beslenme tüpü, servikal özofagostomi, açık ya da laparoskopik gastrostomi ve perkütan floroskopik gastrostomidir. Tüm yöntemlerin birbirlerine üstün ve zayıf yönleri bulunmaktadır (2). Bir ay ve daha kısa süreli oral beslenemeyecek hastalarda nazogastrik veya nazojejunal beslenme tüpleri tercih edilirken, daha uzun süre oral alımı planlanmayan hastalara ise PEG önerilmektedir (3). Başlica PEG endikasyonları; serebrovasküler olay, beyin travması, serebral palsi, nöromüsküler
Background and Aims: Percutaneous endoscopic gastrostomy is the preferred route of enteral feeding in patients who require long-term enteral nutrition. The aim of this study was to perform a retrospective analysis characterizing patients with percutaneous endoscopic gastrostomy. Materials and Methods: We retrospectively evaluated the indications, complications, procedure details, and follow up of patients who underwent percutaneous endoscopic gastrostomy in Gulhane Military Medical Academy, Department of Gastroenterology between 1999 and 2014. Results: Of the 642 patients enrolled, 405 were male (63.1\%), and 237 female (36.9\%). Mean age was 64.2 (range, 18-97) years. Percutaneous endoscopic gastrostomy was successfully performed in all but 7 patients. The most common indication for percutaneous endoscopic gastrostomy tube placement was neurologic disorders in 495 (77.1\%) patients. Other indications were oropharyngeal diseases in 109 (16.9\%) patients, and eosophageal diseases in 38 (6\%) patients. Percutaneous endoscopic gastrostomy related complications were seen in 123 patients (19.1\%). Nine (1.4\%) patients died within 1 month, 15 (2.3\%) patients died within 3 months, and 38 (5.9\%) patients died within 6 months after percutaneous endoscopic gastrostomy procedure. There were no percutaneous endoscopic gastrostomy insertion related mortalities. Conclusion: Percutaneous endoscopic gastrostomy placement to provide enteral access for nutrition support is a safe, minimally invasive, effective, and well-tolerated procedure with a low major complication rate.

Key words: Percutaneous endoscopic gastrostomy, enteral nutrition, indication

bozukluklar, özofagus ve baş-boyun bölgesinin obstrüktif hastalıklarıdır (4). Cerrahi ve radyolojik olarak PEG tüpü takılabilmesine karşın, daha az invaziv ve daha kolay uygulanabilmesi açısıdan endoskopik olarak PEG yerleştirilmesi tercih edilmektedir. Bu bağlamda gastroenteroloji klinikleri ön plana çıkmaktadır. Biz bu çalışmada, PEG uygulaması yaptığımız hastalardaki endikasyonları, işlem sonrası gelişen komplikasyonları ve takipleri ile ilgili verileri değerlendirmeyi amaçladik.

\section{GEREC ve YÖNTEM}

Çalışmaya Mart 1999 - Mart 2014 tarihleri arasında kliniğimiz tarafından PEG takılan hastalar dahil edildi. Hastalar PEG endikasyonları, cinsiyetleri, işlem sonrası gelişen komplikasyonlar, işlem sonrası takip süreleri, aspirasyon ve beslenme intoleransı açısından retrospektif olarak değerlendirildi. Çalışma için GATA etik kurulundan onay alındı. 
Tüm hastalarda enteral besleme, işlemin en az 12 saat öncesinde durduruldu. Hastalara işlemler ya endoskopi ünitesinde ya da yoğun bakımda yatak başında uygulandı. Tüm PEG işlemleri monitörizasyon eşliğinde sedasyon (midazolam 0,1 $\mathrm{mg} / \mathrm{kg}$, en fazla $5 \mathrm{mg}$ ) ve lokal lidokain hidroklorid sprey kullanılarak yapıldı. Hastalara intranazal oksijen desteği verildi ve pulse oksimetre ile kontrolü sağlandı. Isşlemden 30 dakika önce 1 gr sefazolin sodyum proflaktik antibiyotik uygulaması yapıldı. Antikoagülan ve antiagregan ilaç kullanan hastaların ilaçları işlemden 1 hafta önce kesilerek, tedavilerine düşük molekül ağırlıklı heparin eklendi. Öncelikle hastaların üst gastrointestinal sistem endoskopileri yapılarak özofagustan post-bulber bölgeye kadar olan alanda işleme kontrendikasyon oluşturabilecek anatomik bir patoloji olup olmadığı değerlendirildi. Batın ön duvarında işleme engel olabilecek lezyonu olanlar, koagülopati (INR $>1.5$, platelet $<50.000 / \mathrm{mm}^{3}$ ), gastroskopi uygulamasına engel teşkil eden patoloji, gastrik ülser, batında yaygın asit, ciddi psikiyatrik bozukluğa sahip, yaşam beklentisi sınırl, hemodinamik olarak instabil ve bağırsak pasajında ciddi fonksiyon bozukluğu olan hastalara PEG uygulanmadı. Tüm hastalarda işlem iki hekim tarafından gerçekleştirildi. Perkütan girişim sterilizasyon kurallarına hassasiyet gösterilerek, endoskopun ciltten görülebilen parlak ışığı veya parmakla elde edilen fluktuasyonun net olarak görülmesi dikkate alınarak, 'pull-through' tekniği ile yapıldı. Hastalara standart olarak 20 Fr PEG tüpü yerleştirildi. PEG takıldıktan sonra, endoskopik olarak PEG tapasının mukozadaki yeri, pozisyonu, mesafesi ve kanama durumu kontrol edildi. PEG işleminden 6 saat sonra $20 \mathrm{cc}$ su verilerek, karın ağrısı ve PEG kateteri etrafından sızdırma gibi bir sorun olup olmadığı gözlendi. Problem gelişmeyen hastalara $20 \mathrm{cc} / \mathrm{saat}$ ile beslenme başlanarak gittikçe arttırıldı.

\section{BULGULAR}

Kliniğimiz tarafından 1999 - 2014 tarihleri arasında PEG takılan 642 hastanın dosyaları incelenerek verilerine ulaşıldı. 237 hasta kadın (\%36.9), 405 hasta ise erkek (\%63.1) idi. Hastaların yaş ortalaması 64.2 (18-97) yıl idi. 7 hasta dışında tüm hastalara PEG başarılyla yerleştirildi. Bir hastada gastrik kanama, 4 hastada işlem sırasında fluktuasyon veya ışık görülememesi ve 2 hastada ise işlem sırasında gelişen hipoksi nedeniyle PEG takılamadı.

PEG işlemi için hastalardaki en sık endikasyon nörolojik bozukluklardı (495 hasta, \%77.1). Diğer endikasyonlar ise orofaringeal hastalıklar (109 hasta, \%16.9) ve özofageal hastalıklardı (38 hasta, \%6) (Tablo 1). Hastaların ortalama takip süresi 24 ay idi ( 3 gün- 6 yll).

PEG takılmadan önce 335 hasta (\%52.1) nazogastrik beslenme tüpü ile, 147 hasta (\%22.9) total parenteral nutrisyon ile besleniyordu. Kalan 160 hasta (\%25) ise sadece intravenöz hidrasyon alıyordu.
PEG prosedürüne bağlı 123 hastada (\%19.1) komplikasyon gözlendi. Tüm komplikasyonların 101 tanesi minör komplikasyon idi. Bunlar tüp tıkanması 31 (\%4.9), yara enfeksiyonu 22 (\%3.5), lokal ağr 28 (\%4.4), gastrointestinal intolerans 8 (\%1.2), tüpün yer değiştirmesi 10 (\%1.6), tüp kenarından sızıntı 2 (\%0.3) oluşması idi. Yirmi iki hastada ise majör komplikasyon gelişti; gastrik kanama 3 (\%0.4), aspirasyon 8 (\%1.2), buried bumper sendromu $4(\% 0.6)$, peritonit 6 (\%0.8), gastrokütanöz fistül 1 (\% 0.2) (Tablo 2). Işlem nedeniyle hiçbir hastada mortalite gözlenmedi.

Dokuz hasta (\%1.4) PEG işleminden sonraki ilk 1 ay içerisinde, 15 hasta (\%2.3) 3 ay içinde, 38 hasta (\%5.9) ise 6 ay

\begin{tabular}{|lc|}
\hline Tablo 1. PEG endikasyonları & \\
\hline Nörolojik Hastalıklar & $495(\% 77.1)$ \\
\hline Serebral iskemi & $146(\% 22.7)$ \\
\hline Serebral hemoraji & $97(\% 15.1)$ \\
\hline Demans & $89(\% 13.7)$ \\
\hline Kafa travması & $88(\% 13.8)$ \\
\hline Menenjit/Ensefalit & $38(\% 6)$ \\
\hline Parkinson & $19(\% 2.9)$ \\
\hline Amiyotrofik lateral skleroz & $11(\% 1.7)$ \\
\hline Multiple skleroz & $8(\% 1.2)$ \\
\hline Orofarengeal Hastalıklar & $109(\% 16.9)$ \\
\hline Farenks malignitesi & $55(\% 8.5)$ \\
\hline Larens malignitesi & $43(\% 6.7)$ \\
\hline Dil malignitesi & $11(\% 1.7)$ \\
\hline Özofageal Hastalıklar & $38(\% 6)$ \\
\hline Özofagus malignitesi & $35(\% 5.5)$ \\
\hline Özofagus striktür & $3(\% 0.5)$ \\
\hline
\end{tabular}

Tablo 2. PEG komplikasyonları

\begin{tabular}{|l|c|}
\hline Majör Komplikasyonlar & $22(\% 3.2)$ \\
\hline Aspirasyon & $8(\% 1.2)$ \\
\hline Peritonit & $6(\% 0.8)$ \\
\hline Buried bumper sendromu & $4(\% 0.6)$ \\
\hline Gastrik kanama & $3(\% 0.4)$ \\
\hline Gastrokütanöz fistül & $1(\% 0.2)$ \\
\hline Minör Komplikasyonlar & $101(\% 15.9)$ \\
\hline Tüp tıkanması & $31(\% 4.9)$ \\
\hline Lokal ağrı & $28(\% 4.4)$ \\
\hline Yara enfeksiyonu & $22(\% 3.5)$ \\
\hline Tüpün yer değiștirmesi & $10(\% 1.6)$ \\
\hline Gastrointestinal intolerans & $8(\% 1.2)$ \\
\hline Tüp kenarından sızıntı & $2(\% 0.3)$ \\
\hline
\end{tabular}


içinde primer hastalığı nedeniyle kaybedildi. Işlem yapılmış 14 hastada (\%2.2) yutma refleksi sonraki dönemlerde düzeldi ve PEG kateterleri takip eden 6 ay içinde çıkartıldı. 18 hasta (\%2.8) daha sonraki dönemde tüpün yerinden çılkması nedeniyle tekrar başvurdu. Oniki hastaya aynı yerden PEG tüpü takıldı, 6 hasta ise PEG tüpü temin edilinceye kadar foley sonda konarak beslendi, daha sonra PEG tüpüyle değiştirildi. Sekiz hastada erken dönemde gelişen bulantı, kusma ve dispeptik yakınmalar gibi beslenme intoleransı gelişti. Bu hastalarda beslenme volümü azaltıldı, intolerans geriledikten sonra beslenme gittikçe arttırllarak devam edildi.

\section{TARTIŞMA}

Dünyada ilk kez Gauderer tarafından 1980 yllında tarif edilen PEG işlemi, tanımlandığı zamandan günümüze kadar tüm dünyada yaygın olarak kullanılmıştır. Malnütrisyonu olan ve oral beslenmesi yeterli olmayan hastalarda enteral beslenmenin en efektif ve kolay yolu olmuştur (5).

Kliniğimizce PEG takılan 642 hastanın endikasyonlanı değerlendirildiğinde nörolojik hastalıkların ön planda olduğu görülmektedir. Ülkemizde ve dünya literatüründe yayınlanan geniş vakalı çalışmalarda da nörolojik bozukluğu olan hastaların çoğunluğu oluşturduğu görülmektedir (6-8). Bizim çalışmamızda da 495 (\%77.1) hastaya nörolojik bozukluklar nedeniyle PEG takılmıştır. Diğer endikasyonlar incelendiğinde ise baş-boyun tümörleri, uzamış mekanik ventilatör desteği, üst gastrointestinal sistem obstrüksiyonuna yol açan bening ya da malign hastalıklar ve yeterli yutma fonksiyonu olmayan durumlar karşımıza çıkmaktadır $(9,10)$. Bizim çalışmamızda ise nörolojik hastalıklar dışındaki PEG endikasyonları orofaringeal ve özofageal hastalıklardı.

PEG minimal invaziv, etkili ve güvenilir bir işlem olmasına karşın prosedür esnasında veya sonrasında bazı komplikasyonlar oluşabilmektedir. En sık görülen komplikasyonlardan biri olan lokal enfeksiyon riskini azaltmak için antibiyotik proflaksisi literatürdeki birçok çalışma tarafından önerilmektedir $(11,12)$. Antibiyotik profilaksisi PEG giriş yeri enfeksiyonların azaltmada önemli rol oynamaktadır $(13,14)$. Bizim çalışmamızda, 22 (\%3.4) hastada PEG kateteri çevresinde enfeksiyon gelişti. Verilen antibiyoterapi ile hızlı bir şekilde tedavi oldukları gözlendi. PEG işlemine bağlı diğer komplikasyonlar özofagus ya da batın içi organ perforasyonları, PEG tüpünün tıkanması, lokal ağrı, gastrointestinal intolerans, tüpün yer değiştirmesi, tüp kenarından sızıntı, gastrik kanama, aspirasyon pnömonisi, buried bumper sendromu, peritonit, gastrokutanöz fistül, sepsis ve pnömoperitoneumdur (1517). Serimizdeki PEG komplikasyonları değerlendirildiğinde; 22 hastada (\%3.2) önemli majör komplikasyon gelişmiştir [Gastrik kanama $3(\% 0.4)$, aspirasyon 8 (\%1.2), buried bumper sendromu 4 (\%0.6), peritonit $6(\% 0.8)$, gastrokutanöz fistül 1 (\%0.2)]. PEG takılmasına sekonder oluşan mortalite \% l'in altında bildirilmiştir (18). Bizim hastalarımızda PEG işlemine bağlı mortalite görülmedi.

PEG ile ilişkili işlemlere bakıldığında bir grup hastada PEG takıldıktan sonra durumunda düzelme olduğu ve PEG tüplerinin yeniden çıkartıldığı görülmektedir. Bu durum aslında, PEG işleminin hastanın primer hastalığının iyileşmesine olan önemli katkıyı göstermesi açısından önemlidir. Srinivasan ve ark. yaptığı çalışmada 601 PEG işleminin 49 (\%8.1) tanesi PEG çıkartma prosedürüdür (6). Ülkemizden Şit M ve ark. yaptığı çalışmada ise 104 olgudan sadece 3’ü (\%2.8) PEG çıkartma işlemi olarak görülmüştür (19). Bizim olgularımızda, 23 vakada (\%3.6) sonraki dönemlerde yutma fonksiyonlarının düzelmesi neticesinde PEG tüpü çıkartılmıştır. Çalışmalar arasındaki PEG çıkartma oranlarının farklı olmasının sebebi, PEG endikasyonu saptanırken gösterilen yaklaşım olabilir. Tamamen düzelmesi beklenmeyen kronik ve malign hastalıklara sahip, özellikle yaşlı hastalara takılan PEG tüpleri bu oranların değişmesine neden olmaktadır.

Çalışmamızdaki en önemli limitasyon, hastaların beslenme parametrelerinin net olarak değerlendirilememiş olmasıdır. Çalışma retrospektif olduğundan dolayı hastaların ağırlıkları ve serum albümin düzeyleri peryodik olarak ölçülememiştir.

Sonuç olarak bu çalışmada; PEG işleminin güvenli, pratik, etkili, iyi tolere edilen ve düşük majör komplikasyon oranına sahip bir prosedür olduğu değerlendirilmiştir.

\section{KAYNAKLAR}

1. Gauderer MW, Ponsky JL, Izant RJ Jr. Gastrostomy without laparotomy:a percutaneous endoscopictechnique. J Pediatr Surg 1980;15:872-5.

2. Cantwell CP, Gervais DA, Hahn PF, Mueller PR. Feasibility and safety of infracolic fluoroscopically guided percutaneous radiologic gastrostomy. J Vasc Interv Radiol 2008;19:129-32.

3. Ermis F, Ozel M, Oncu K, et al. Indications, complications and long-term follow-up of patients undergoing percutaneous endoscopic gastrostomy: A retrospective study. Wien Klin Wochenschr 2012;124:148-53.

4. Nicholson FB, Korman MG, Richardson MA. Percutaneous endoscopic gastrostomy: a review of indications, complications and outcome. J Gastroenterol Hepatol 2000;15:21-5.

5. Gauderer M. Twenty years of percutaneous endoscopic gastrostomy: origin and evolution of a concept and its expanded applications. Gastrointest Endosc 1999;50:879-83.

6. Srinivasan R, Irvine T, Dalzell M. Indications for percutaneous endoscopic gastrostomy and procedure-related outcome. J Pediatr Gastroenterol Nutr 2009;49:584-8.

7. Fortunato JE, Troy AL, Cuffari C, et al. Outcome after percutaneous endoscopic gastrostomy in children and young adults. J Pediatr Gastroenterol Nutr 2010;50:390-3.

8. Cantez MS, Cantez S, Gerenli N, Durmaz Ö. Demographic findings of 104 patients with percutaneous endoscopic gastrostomy. Türk Ped Arş 2013;210-4. 
9. Yllmaz H, Alptekin H, Acar F, et al. Experience of percutaneous endoscopic gastrostomy. Selçuk Tip Derg 2013;29:68-70.

10. Herman LL, Hoskins WJ, Shike M. Percutaneous endoscopic gastrostomy for decompression of the stomach and small bowel. Gastrointest Endosc 1992;38:314-8.

11. Sharma VK, Howden CW. Meta-analysis of randomized, controlled trials of antibiotic prophylaxis before percutaneous endoscopic gastrostomy. Am J Gastroenterol 2000;95:3133-6.

12. Lipp A, Lusardi G. A systematic review of prophylactic antimicrobials in PEG placement. J Clin Nurs 2009;18:938-48

13. Jain NK, Larson DE, Schroeder KW, et al. Antibiotic prophylaxis for percutaneous endoscopic gatrostomy: A prospective, randomized controlled clinical trial. Ann Intern Med 1987;107:824-8.

14. Pien ECT, Hume K, Pien FD. Gastrostomy tube infections in a community hospital. Am J Infect Control 1996;24:353-8.
15. Gottfried EB, Plumser AB, Clair MR. Pneumoperitoneum following percutaneous endoscopic gastrostomy. A prospective study. Gastrointest Endosc 1986;32:397-9.

16. Hull MA, Rawlings J, Murray FE, et al. Audit of outcome of long-term enteral nutrition by percutaneous endoscopic gastrostomy. Lancet 1993;341:869-72.

17. Finocchiaro C, Galletti R, Rovera G, et al. Percutaneous endoscopic gastrostomy: a long-term follow-up. Nutrition 1997;13:520-3.

18. Foutch P. Complications of percutaneous endoscopic gastrostomy and jejunostomy. Recognition, prevention and treatment. Gastrointest Endosc Clin N Am 1992;2:231-48.

19. Şit M, Kahramansoy N, Tekelioğlu ÜY, Ocak, T. Our experience in percutaneous endoscopic gastrostomy. Journal of Academic Research in Medicine 2013;3:66-8 